\title{
INTENÇÕES E AÇÕES EM RELAÇÃO A EscolHAS DE PRODUTOS ECOLÓGICOS: ESTUDOS SOBRE O COMPORTAMENTO DO CONSUMIDOR CARIOCA
}

\section{RESUMO}

$\mathrm{O}$ artigo apresenta o resultado de pesquisas realizadas sobre atitudes e comportamentos de compra de consumidores de diferentes tipos de bens com características ecológicas. O objetivo é avaliar o valor atribuído a essas características por grupos de consumidores e identificar variáveis que estejam associadas a essas escolhas. O método utilizado é a análise conjunta, complementado por dados qualitativos. Fizeram parte dos estudos 469 consumidores. Os resultados revelam que nem sempre atitudes favoráveis se traduzem em escolhas compatíveis. Conclui-se que o valor dado a ofertas ecológicas varia em função do tipo de produto, está mais relacionado às mulheres e em particular com nível de instrução superior.

Palavras-chave: Produtos ecológicos, marketing verde, comportamento do consumidor, consumo sustentável, atitude.

\section{ABSTRACT}

The article presents the result of pieces of research on consumers' attitude and purchasing behavior on different types of goods with environmental characteristics. The objective is to assess the value attributed to ecological characteristics by groups of consumers and identify variables that are associated to their choices. The method used is the conjoint analysis, complemented by some qualitative data. 469 consumers took part in the studies. The results show that favorable attitudes not always result in consistent choices. It is concluded that the value given to ecological offerings varies by product type, is more related to women and those with higher level of education.

Key words: Ecological products, green marketing, consumer behavior, responsible consumption, attitude.

\section{André Lacombe Rocha}

PhD e MSc em Economia Agrícola pela University of London.

Pós-Graduação em Marketing pelo $I A G$, Bacharel em Administração pela PUC-Rio. Atualmente é professor e pesquisador nas áreas de Marketing, Meio Ambiente e Logística no IAG, PUC-Rio. lacombe@iag.puc-rio.br
Recebido em 15/janeiro/2011 Aprovado em 27/junho/2011 


\section{INTRODUÇÃO}

As últimas décadas têm mostrado uma taxa de degradação ambiental em escala global, a qual tem causado preocupação a gestores de um modo geral. Conceitos como marketing ambiental, sustentabilidade, consumo consciente, consumo sustentável, entre outros, têm ganhado força e espaço na agenda de estrategistas de negócios, de modo a encontrar segmentos de mercado sensíveis aos apelos ecológicos Embora seja razoável assumir que consumidores vão dar preferência a produtos que afetam o meio ambiente em menor intensidade, evidências nesse sentido ainda são escassas.

$\mathrm{Na}$ última década, autores como Crespo e Leitão (1993), Marques (1998), Hill (1999), Lages e Neto (2002), Motta e Rossi (2003), Palhares (2003); Bedante e Slongo (2004), Pereira et al. (2004), Rocha e Marques (2004), Faggiani (2005), Instituto Akatu (2006), Castro (2006), Rocha (2006; 2007); Schenini et al. (2006), Almeida et al. (2007), Rocha e Santos (2007), Baisch (2008), Motta (2008), entre outros, vêm pesquisando o comportamento do consumidor brasileiro em relação aos produtos ecologicamente corretos no mercado. Esses autores estudaram atitudes e comportamentos dos consumidores, assim como a disposição deles de se privarem de determinadas comodidades, ou alterarem seus hábitos, a fim de contribuírem de alguma forma com o meio ambiente. Buscaram verificar, ainda, a predisposição dos consumidores a pagarem preços maiores para consumir produtos ecologicamente corretos, caso necessário.

Sob o ponto de vista de marketing, a oferta de produtos depende da identificação de um ou mais segmentos de mercado que mostrem interesse por eles. Segundo Guimarães (2006), para determinados segmentos de mercado o consumidor se tornou mais crítico na escolha do produto ou serviço, assim como se tornou também mais cético em relação ao teor das mensagens criadas pelos anunciantes para promover os atributos ecológicos de seus produtos. Céticos também em relação ao verdadeiro comprometimento das empresas com a preservação do meio ambiente.

Diante desse cenário de degradação dos atuais padrões de produção e consumo e do relativo desconhecimento sobre o perfil da real demanda por produtos ecológicos, este trabalho se propõe a responder as seguintes questões:
Qual é o valor percebido por consumidores em relação às características ecológicas de produtos quando comparadas com outras variáveis também importantes no seu processo decisório de compra? Que características dos produtos e consumidores estão mais relacionadas à percepção de valor atribuído a esses produtos? Até que ponto atitudes favoráveis a produtos ecológicos por parte dos consumidores são coerentes com suas escolhas?

\section{OBJETIVOS}

Este estudo tem como objetivo central revelar resultados de pesquisas realizadas sobre o valor atribuído por consumidores do Rio de Janeiro a variáveis com características ecológicas presentes em 9 diferentes bens de consumo. Pretende também identificar quais características desses produtos e consumidores estão mais relacionadas à percepção de valor atribuído pela amostra estudada. Por fim, busca avaliar a coerência entre as atitudes dos respondentes no que concerne a esses produtos e as suas escolhas feitas durante as pesquisas, respondendo assim às questões apresentadas acima. Estima-se que tais objetivos complementem os conhecimentos disponíveis na literatura até o momento e auxiliem gestores de marketing a melhor identificar os comportamentos de compra e os perfis de alguns segmentos que compõem os mercados dos diferentes tipos de produtos ecológicos.

\section{REFERENCIAL TEÓRICO}

Embora a degradação dos recursos naturais por parte das atividades humanas tenha sido uma preocupação dos economistas há muitas décadas (PIGOU, 1920; COASE, 1960; CHEUNG, 1973), aparentemente foi apenas no final do século passado que o tema chegou de forma mais contundente ao âmbito empresarial. A discrepância entre o produto líquido das atividades econômicas no âmbito privado e o produto líquido no âmbito social gera externalidades que se revelam muitas vezes danosa ao meio ambiente. Isto é, relações de troca entre empresas e consumidores refletem seus custos e benefícios, e não necessariamente os danos causados a terceiros. Quando tais efeitos são levados em consideração, aproximamonos do conceito de sustentabilidade, o qual implica o uso de recursos, tanto na produção quanto no consumo, 
sem sacrificar a sociedade ou os próprios envolvidos em momentos futuros.

A preocupação com a manutenção das condições de oferta dos suprimentos necessários para atender às demandas atuais e futuras, berço do conceito de sustentabilidade, veio somar-se à preocupação de alguns empresários em atender bem aos seus mercados-alvo sem sacrificar o bem-estar da sociedade em geral. Essa nova orientação empresarial, denominada de marketing social (KOTLER, 1998), tem envolvido tanto aspectos sociais quanto ecológicos na forma de sanar as demandas dos consumidores. O conceito de sustentabilidade, seja na produção, seja no consumo, assim como o consumo consciente e o chamado marketing ambiental, passaram a se popularizar principalmente nas últimas duas décadas (OTTMAN, 1994; MINTU-WINSATT; BRADFORD, 1995; WASIK, 1996; WAGNER, 1997; HART, 1997; REINHARDT, 2000; ASHLEY, 2002; MANZINI; VEZZOLLI, 2002; BEDANTE; SLONGO, 2004; PEREIRA et al., 2004; GONÇALVES-DIAS; MOURA, 2007; ROCHA; SANTOS; 2007; OTTMAN, 2007; INSTITUTO AKATU/ETHOS, 2008; MOTTA, 2008; COHN et al., 2009; ZWERG-VILLEGAS, 2009).

A lógica dessa filosofia empresarial está, portanto, no argumento de que um produto que atenda às necessidades ou aos desejos de seu público, e que, além disso, tenha um menor impacto sobre as demais pessoas e o meio ambiente, provavelmente será reconhecido como mais competitivo do que os demais aos olhos desse público. Ainda, pressupõe que o atributo com um menor dano ambiental seja valorizado a ponto de justificar sua escolha em detrimento de outras ofertas (OTTMAN, 1994). Esses produtos têm sido chamados de "ecológicos" ou "ecologicamente corretos" e na concepção de Ottman (1994) são definidos como aqueles que consomem menos energia - seja na produção, seja no seu consumo -, que são mais duráveis, não tóxicos, feitos de materiais reciclados ou recicláveis e com o mínimo de embalagem possível.

A despeito do mérito dessa lógica, há evidências de que muitos consumidores são céticos em relação a esses atributos e, portanto, não necessariamente reconhecem nessas ofertas um valor superior ou uma imagem significantemente distinta das demais concorrentes (BANSAL; ROTH, 2000; CHEN, 2001; GUIMARÃES; 2006; ROCHA, 2007; ROCHA; SANTOS, 2007; COHN et al., 2009). Outros autores encontraram evidências de que produtos ecológicos nem sempre são mais competitivos, embora as razões não sejam claras o suficiente (ELKINGTON et al., 1990; PORTNEY, 1990; HART, 1997; WAGNER, 1997; JOHANSSON, 1998; WATSON, 1998; LAGES; NETO, 2002; NEWTON, 2002; PALHARES, 2003; ROCHA; MARQUES, 2004; PEREIRA et al., 2004; ROCHA, 2006; SCHENINI et al., 2006; CORNELISSEN et al., 2007; ROCHA, 2007; ROCHA; SANTOS, 2007; CORNELISSEN et al., 2008; INSTITUTO AKATU/ETHOS, 2008; AZEVEDO et al., 2009).

De fato, compreender o comportamento humano não é uma tarefa simples. Da mesma forma são complexos os processos de análise e decisão de compra dos consumidores (SOLOMON, 2002). Em primeiro lugar porque consumidores têm diferentes percepções sobre o mundo ao seu redor. Também apresentam diferentes níveis de conhecimento sobre as ofertas de soluções disponíveis para sanar suas necessidades e seus desejos. Soma-se a isso ainda o fato de atribuírem diferentes significados às categorias de produtos e serviços, o que implica o envolvimento do mundo da abstração, resultando no processo de atribuição de valor.

A percepção de valor está relacionada às características dos consumidores, dos produtos e aos benefícios que podem proporcionar. Portanto, para compreender como consumidores fazem suas escolhas é necessário conhecer os significados que atribuem aos produtos que compram ou consomem. Parte desse processo pode ser feito com base na identificação dos valores dados às diferentes características dos produtos sob análise, as quais são entendidas como determinantes de suas atitudes e eventualmente de suas decisões finais de compra e consumo.

Engel et al. (2000) definem atitude como apreço ou aversão que os consumidores apresentam em relação a determinado produto, resultado de suas crenças, experiências e seus sentimentos. Ou seja, a atitude seria compreendida como uma avaliação geral sobre um objeto, a qual desempenha um papel importante na forma como se comportam os consumidores. Ainda segundo esses autores, a atitude tem sido vista, tradicionalmente, como uma formação de três componentes: cognitivo, afetivo e conativo: 


\begin{abstract}
"O conhecimento e as crenças de uma pessoa sobre algum objeto de atitude residem no componente cognitivo. O componente afetivo representa os sentimentos de uma pessoa em relação ao objeto da atitude. O componente conativo refere-se às tendências de ação ou comportamentais da pessoa em relação ao objeto da atitude" (ENGEL et al., 2000, p. 240).
\end{abstract}

Contudo, esses mesmos autores apresentam outra visão, mais contemporânea, da definição de atitude. Segundo eles, a atitude seria percebida como um fator distinto de seus componentes, embora cada um desses componentes esteja relacionado à atitude. Por exemplo, os componentes cognitivos (aprendizado e crenças) e afetivos (sentimentos) estariam classificados como determinantes das atitudes, enquanto as atitudes determinariam o componente conativo (intenções). Em outras palavras, “[...] a avaliação geral de uma pessoa sobre um objeto de atitude é vista como determinada pelas crenças e/ ou sentimentos da pessoa sobre o objeto da atitude" (ENGEL et al., 2000, p. 241). Como consequência, “[...] as intenções comportamentais de uma pessoa dependerão de suas atitudes" (ENGEL et al., 2000, p. 242). A Figura 1 ilustra essas relações.

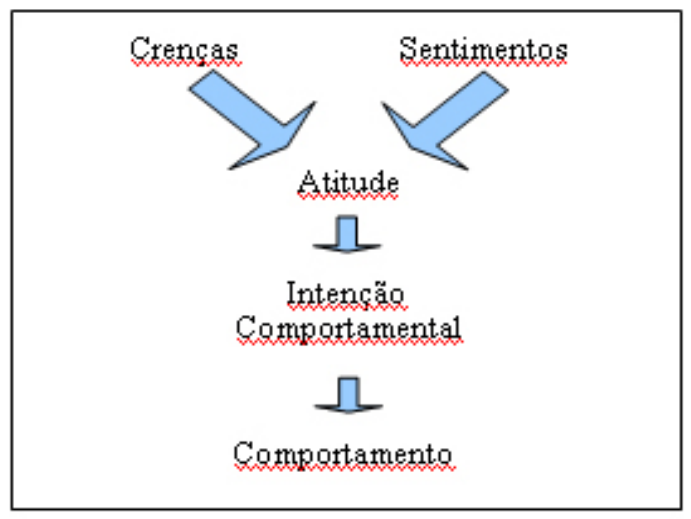

Figura 1: Um Modelo de Construção de Comportamento (Adaptado de ENGEL et al., 2000, p. 241).

Conforme a figura 1, as duas formas fundamentais pelas quais seriam formadas as atitudes são as crenças e os sentimentos sobre o objeto em questão. Por sua vez, a relação de predominância entre crenças e sentimentos no comportamento de consumo vai depender de diversos fatores, entre eles, a natureza do produto. A identificação da maneira pela qual são formadas as atitudes é relevante, pois fornece orientação para quem busca entender e influenciar a intenção de compra ou de consumo do consumidor.

Ainda segundo o modelo, o fato de a intenção comportamental estar mais próxima da ação de compra significa que a decisão de comprar ou não está mais ligada à intenção comportamental do que à atitude. Por essa razão, os autores argumentam que quando um profissional de marketing busca "prever comportamento, a intenção comportamental deve ser medida porque ela deve render uma previsão mais exata do comportamento futuro" (ENGEL et al., 2000 p. 242). Esse argumento tem servido de base para a identificação dos perfis de atitude, intenções e comportamento dos grupos pesquisados nesses últimos anos em relação a produtos com apelos ecológicos.

Os autores do presente artigo realizaram, no passado, estudos que revelam algumas contradições entre as atitudes de grupos de consumidores em relação a produtos ecológicos e ao meio ambiente, em geral, e suas respectivas intenções comportamentais. Isto é, nem sempre o que os respondentes declaram aprovar se traduz em ações condizentes. Os estudos, em outras palavras, sinalizam que atitudes favoráveis não garantem decisões de compra em relação a produtos com características ecológicas.

Outros autores também concluíram que decisões tomadas por indivíduos tendem a mostrar uma preocupação ambiental menor do que a consciência social ou os fatores econômicos, o que contrasta com a proposição de que produtos ecológicos têm um valor superior ou representam necessariamente uma vantagem competitiva em relação aos demais (DOBSON, 1990 in NEWTON, 2002; PORTNEY, 1990; HART, 1997; BANSAL; ROTH, 2000; CHEN, 2001; NEWTON, 2002; OTTMAN, 2007). Neste artigo apresenta-se resultados de pesquisas que identificam o valor dessas variáveis diante de outras igualmente importantes.

\section{MÉTODO}

As variáveis ecológicas estudadas em cada produto foram aquelas apresentadas pelos produtores como de menor impacto ambiental. O método utilizado mensura 
o peso dessas variáveis ecológicas no processo decisório de compra em face de outras variáveis consideradas relevantes, com base numa simulação, assim como identifica as razões existentes por trás das escolhas feitas. Utiliza-se dados demográficos dos respondentes para identificar eventuais sinais de segmentação. Os resultados obtidos são analisados de modo a lançar luz sobre o comportamento de compra desses consumidores e assim fornecer subsídios para gestores marketing.

O principal método utilizado é a análise conjunta (WIND, 1978; GREEN; SRINIVASAN, 1990; HERMAN; KLEIN, 1995). A principal vantagem desta abordagem é o realismo que dá à pesquisa (FRANÇOIS; MacLACHLAN, 1995; KAUL; RAO, 1995; MALHOTRA, 2006).O método reflete a efetiva situação com a qual consumidores se deparam quando têm de decidir sobre a compra de produtos. Esse método é complementado por uma técnica de análise qualitativa com o fim de levantar as atitudes dos respondentes em relação aos produtos estudados.

O primeiro passo da pesquisa é a escolha de um produto que tenha alguma característica ecológica que justifique o apelo comercial feito pelos seus fabricantes. Posteriormente, realiza-se uma pesquisa exploratória com um pequeno grupo de consumidores e compradores do produto em particular, com a finalidade de levantar os atributos considerados por eles como os mais relevantes no processo de escolha de suas compras.

A definição das principais variáveis de estudo (atributos) e de seus níveis toma como base essas considerações. Procede-se, então, a uma análise de frequência para identificar as variáveis mais citadas pelos respondentes. Quando a variável de caráter ecológico, e portanto de maior interesse destes estudos, não aparece entre as quatro principais comentadas, a quarta variável mais citada é substituída por ela. O procedimento tem o objetivo de reduzir o estudo a quatro variáveis e a 12 níveis para cada produto. $\mathrm{O}$ motivo é que com esse número de variáveis e níveis é possível restringir o número de combinações e escolhas a um grau gerenciável no momento da pesquisa de campo.

Os níveis de cada variável são determinados com base nos relatos dos entrevistados durante a fase exploratória, posteriormente complementada por um trabalho de campo. Por exemplo, se as variáveis “marca" e "preço" aparecem entre as mais citadas nessa fase exploratória de entrevistas e, por conseguinte, são selecionadas, uma pesquisa de campo se faz necessária para identificar faixas de preços de diferentes marcas. Nesse momento, quatro preços e quatro marcas são selecionados: um preço baixo, relativo a uma marca posicionada para o segmento que busca economia; um preço superior, referente a uma marca posicionada pelo prestígio, e dois preços medianos, relativos a duas outras marcas intermediárias. As outras duas variáveis selecionadas são representadas por apenas dois níveis cada uma. Se a variável “embalagem” é selecionada como muito relevante no processo de escolha, então se procura identificar dois tipos distintos de embalagens disponíveis para o produto, como reaproveitável ou não. Por fim, se a variável "tipo de ingrediente" também for selecionada, outros dois tipos alternativos são identificados, a exemplo de químico ou natural.

As quatro variáveis selecionadas e os 12 níveis de cada produto resultam em 16 combinações, todas diferentes entre si, representadas por cartões que são apresentados aos entrevistados como um instrumento de simulação de decisão de compra. Os cartões pretendem representar 16 diferentes ofertas do produto sob análise. Os entrevistados são convidados a ordenar os 16 cartões em ordem de preferência. Dessa forma, é possível observar como os entrevistados avaliam as variáveis (ou atributos) em relação umas às outras. A combinação das variáveis e de seus níveis é feita tomando-se por base um arranjo fracionário, elaborada pelo método full-profile, de modo que as variações sãolsejam ¿¿ baseadas nos níveis e não nos atributos (MOTTA, 1997). Os níveis variam de 0,0 a 1,0; quanto maior o número, maior é o valor (a utilidade) atribuído a ele. Nesses estudos, assume-se, como restrição, que as quatro variáveis selecionadas representam 100\% do valor considerado no processo decisório de compra. Nesse caso, as avaliações dos pesos das variáveis variam de $0 \%$ a $100 \%$ cada, e o somatório dos pesos das quatro variáveis totaliza $100 \%$. Os dados são processados em um software específico, construído dentro da plataforma Excel (SILVA, 1998; HILL, 1999).

Durante a fase de coleta de dados no campo, em nenhum momento é informada a natureza ou o objetivo do estudo. A razão é evitar algum tipo de viés em relação às escolhas das variáveis ecológicas. Esse procedimento difere daquele utilizado por Cornelissen et al. (2008), que 
buscou identificar até que ponto a explícita introdução ao tema desperta uma disposição para a escolha de produtos mais ecológicos.

Nos estudos aqui descritos, os entrevistados são primeiramente convidados a classificar os cartões (opções) em ordem de preferência, como se realmente estivessem diante de um processo decisório de compra do produto em questão (intenção comportamental). Para fazer parte da pesquisa, são selecionados apenas compradores regulares, e nenhuma menção é feita nesse momento sobre a natureza da pesquisa.

Depois de ordenarem as opções um questionário é preenchido pelos participantes. Quando possível uma entrevista não estruturada é realizada após o preenchimento do questionário. O objetivo é coletar informações sobre as atitudes, as percepções e as intenções comportamentais dos participantes em relação a produtos ecológicos em geral, e em respeito às variáveis ecológicas contidas no estudo em particular. Serve também para coletar dados demográficos que permitam descrever o perfil dos respondentes e realizar análises por segmentos. Nove estudos são aqui relatados, referentes a produtos estudados nesses 10 últimos anos. São eles: ovos embalados, detergente, inseticida, creme hidratante para o corpo, pneus, jóias, artigos de decoração, pilhas e cadernos, envolvendo 469 pessoas. A seleção desses produtos teve como objetivo cobrir um leque amplo de bens de consumo com diferentes características, tais como valor, tipo de apelo ecológico, tipo de uso e nível de contato com o corpo. Os resultados são resumidos abaixo.

\section{RESULTADOS}

\section{Ovos embalados}

Promoveu-se, em 1999, a primeira pesquisa com o intuito de avaliar o valor percebido por compradores de ovos em relação à embalagem de papelão feita com polpa de papel reciclado. Empresas especializadas apresentam como apelo comercial em seus veículos de comunicação o fato de essa embalagem ser um produto ecologicamente mais correto. Fez-se uma pesquisa em granjas compradoras de formas de ovos de papelão para identificar o peso desse argumento de venda no seu processo decisório. Foram obtidas pouquíssimas respostas, o que levou os pesquisadores a abordarem os compradores finais, em particular os consumidores individuais.

Realizou-se uma pesquisa de campo com um grupo de consumidores e compradores de ovos, que ajudou a identificar as variáveis consideradas mais relevantes no seu processo de escolha: tamanho do ovo, cor do ovo, prazo de validade e preço. Levando em conta que somente são comercializados produtos com prazo de validade, essa variável foi substituída por "tipo de embalagem". Os níveis foram identificados no campo. São eles: embalagem (papelão, plástico, isopor, jornal); tamanho (grande e pequeno); cor (branco e vermelho); preço da dúzia ( $\mathrm{R} \$ 1.00, \mathrm{R} \$ 1.20, \mathrm{R} \$ 1.35, \mathrm{R} \$ 1.50)$. Essas variáveis e seus níveis geraram as 16 combinações previstas, as quais foram submetidas a 122 consumidores e compradores regulares entre 1999 e 2000 . Os resultados estão resumidos na na Tabela 1.

Considerando as variáveis selecionadas - os quatro atributos e seus 12 níveis -, observa-se que o maior peso do processo decisório dessa amostra reside no preço, com $40 \%$ do total, seguido de tamanho e tipo de embalagem, ambos com 28\%, e cor, com 5\% apenas. Os níveis da variável de interesse "embalagem" receberam os seguintes graus de utilidade: papelão $(0,74)$, isopor $(0,70)$, plástico $(0,62)$ e jornal $(0,05)$. O primeiro e o último são considerados os mais ecológicos, sendo papelão o nível de maior interesse dos pesquisadores. Considerando os quatro atributos mais relevantes, "embalagem" aparece entre segundo e terceiro lugar no grau de importância. Contudo, analisando os diferentes tipos (níveis), nota-se que o preferido é o papelão, embora apenas marginalmente acima do isopor, o menos ecológico dos quatro.

Tabela 1: Nível de utilidade dos atributos de ovos embalados (\%)

\begin{tabular}{|c|c|c|c|c|c|c|c|c|}
\hline OVOS & Cor & Embalagem & Preço & Tamanho & $\begin{array}{l}\text { Embalagem } \\
\text { de Papelão }\end{array}$ & $\begin{array}{c}\text { Embrulhado } \\
\text { em Jornal }\end{array}$ & $\begin{array}{l}\text { Embalagem } \\
\text { Plástica }\end{array}$ & $\begin{array}{l}\text { Embalagem } \\
\text { de Isopor }\end{array}$ \\
\hline Amostra (122) & 5 & 28 & 40 & 28 & 0,74 & 0,05 & 0,62 & 0,70 \\
\hline Homens (52) & 4 & 28 & 41 & 27 & $\mathbf{0 , 7 3}$ & 0,06 & 0,64 & 0,73 \\
\hline Mulheres (70) & 6 & 27 & 38 & 28 & 0,75 & 0,04 & 0,60 & 0,71 \\
\hline Educação Superior & 6 & 32 & 32 & 30 & 0,84 & 0 & 0,71 & 0,79 \\
\hline Educacão Inferior (39) & 4 & 19 & 53 & 23 & $\mathbf{0 , 6 7}$ & 0,31 & 0,58 & 0,64 \\
\hline
\end{tabular}


Observações coletadas no questionário submetido aos respondentes após o exercício da simulação mostram que a grande maioria deles reconhece na embalagem de papelão uma relação com o meio ambiente. Algunsconsideraramaembalagem plástica também ecológica, sob

Tabela 2: Nível de utilidade dos atributos de detergente (\%)

\begin{tabular}{|c|c|c|c|c|c|c|}
\hline DETERGENTE & Cheiro & Biodegradabilidade & Preço & Marca & $\begin{array}{c}\text { Bio } \\
(\text { Sim })\end{array}$ & $\begin{array}{c}\text { Bio } \\
(\text { Não })\end{array}$ \\
\hline Amostra (40) & 6 & 24 & $\mathbf{4 1}$ & 28 & $\mathbf{0 , 7 8}$ & 0,20 \\
\hline Mulheres (23) & 11 & $\mathbf{3 2}$ & 24 & $\mathbf{3 3}$ & $\mathbf{1 , 0}$ & 0,1 \\
\hline Homens (17) & 0 & 14 & $\mathbf{6 5}$ & 21 & $\mathbf{0 , 6 0}$ & 0,39 \\
\hline $\begin{array}{c}\text { Educação Superior } \\
\text { (22) }\end{array}$ & 10 & $\mathbf{3 8}$ & 18 & 34 & $\mathbf{1 , 0}$ & 0,06 \\
\hline $\begin{array}{c}\text { Educação Inferior } \\
\text { (18) }\end{array}$ & 1 & 9 & $\mathbf{6 9}$ & 21 & $\mathbf{0 , 5 6}$ & 0,44 \\
\hline Renda Alta (16) & 6 & $\mathbf{3 8}$ & 26 & 29 & $\mathbf{1 , 0}$ & 0,0 \\
\hline Renda Baixa (10) & 3 & 2 & $\mathbf{6 9}$ & 26 & $\mathbf{0 , 5 1}$ & $\mathbf{0 , 4 9}$ \\
\hline
\end{tabular}
o argumento de que pode ser reciclada. Em trechos específicos do questionário, a maioria dos respondentes afirmou se considerar uma pessoa preocupada com o meio ambiente e muitos manifestaram preferência por produtos com características ecológicas. Contudo, pouquíssimos entrevistados afirmaram ter feito qualquer relação entre as escolhas feitas durante a simulação e o meio ambiente. Ou seja, a eventual preferência pela embalagem de papelão (ou mesmo de plástico) não guardou relação com uma escolha ecológica, com poucas exceções. Esse pequeno grupo de exceções era composto principalmente de mulheres. Dados indicaram também que os respondentes com grau de instrução superior eram mais propensos à preferência por embalagem de papelão, em particular as mulheres. Assim, concluiu-se que o segmento feminino se mostra o mais interessado nesse tipo de embalagem, embora apenas discretamente com alguma ligação à lógica do consumo ecológico.

Entre 2002 e 2003 dois outros produtos, detergente e inseticida, foramobjetode estudocomamesmasistemática. O estudo com detergente envolveu as seguintes variáveis: preço, marca, cheiro e biodegradabilidade. O estudo com inseticida baseou-se nos mesmos procedimentos descritos acima. No total, 120 pessoas participaram da pesquisa, embora tenham sido considerados válidos apenas 39 questionários preenchidos sobre inseticidas e 40 sobre detergentes. Os principais resultados seguem abaixo.

\section{Detergente}

As variáveis e os níveis selecionados neste estudo foram: preço ( $\mathrm{R} \$ 0.55, \mathrm{R} \$ 0.64, \mathrm{R} \$ 0.74, \mathrm{R} \$ 0.82)$; marca (ODD, Limpol, Minerva, Barra); cheiro (com ou sem); biodegradabilidade ( $\operatorname{sim}$ ou não). Os resultados referentes ao peso das variáveis selecionadas e os níveis de utilidade dos dois tipos de ingredientes dos detergentes são resumidos na Tabela 2 .

Uma análise específica dos graus de utilidade atribuídos à variável biodegradabilidade mostrou uma clara preferência por sua presença (Bio Sim), em uma proporção 0,78/0,20. Os dados sugerem que, dada a opção de escolha entre a biodegradabilidade ou não, a atitude dos compradores é favorável a ela, em princípio, o que representaria um atributo potencialmente valioso no processo decisório de compra. Contudo, uma vez que representa apenas o terceiro fator de importância (24\%), atrás de variáveis como marca (28\%) e preço (41\%), esse atributo para a amostra não se mostrou forte o suficiente.

Na avaliação dos dados por gênero, embora a amostra seja pequena, observa-se que as mulheres se mostram mais sensíveis ao atributo, conferindo-lhe um peso consideravelmente superior ao atribuído pelos homens (32\% e 14\% respectivamente). Quando segmentado por grau de instrução, fica evidente o maior valor percebido por aqueles com grau superior, com $38 \%$ do peso da escolha contra $9 \%$ dos respondentes com grau inferior. O mesmo fenômeno é observado quando os dados são analisados por faixa de renda: alta $(38 \%)$ e baixa $(2 \%)$, sugerindo que quanto maior a renda do comprador mais valorizada a biodegradabilidade no seu processo decisório de compra. A combinação desses resultados revela que o público feminino com grau de instrução e renda superior é o segmento mais propenso a optar por esse atributo em detergentes.

\section{Inseticida}

Os atributos e níveis analisados nesta pesquisa foram: preço ( $R \$ 3.90, R \$ 4.00, R \$ 4.89, R \$ 5.10)$; marca (UFFA, SBP, Rodasol, Baygon); biodegradabilidade (sim e não); cheiro (com e sem). Os resultados são resumidos na Tabela 3.

A amostra revelou dois atributos como os mais relevantes no processo decisório, dadas as variáveis 
analisadas: preço (30\%) e biodegradabilidade (30\%). Marca (16\%) e cheiro (19\%) seguiram em terceiro e quarto lugar respectivamente. Este resultado é surpreendente, pois coloca o atributo ecológico em primeiro lugar. Comentários feitos nos questionários oferecem uma possível razão: preocupação com a segurança do ambiente. Uma análise específica do grau de utilidade da variável biodegradabilidade mostra uma clara preferência por sua presença em todos os subgrupos. “biodegradável”, parece despertar nos consumidores uma maior consideração em relação a esse tipo de ingrediente. Assim sendo, é provável que o apelo ecológico presente na fórmula biodegradável tenha um papel apenas secundário no processo de avaliação e escolha desse grupo, o que lança uma grande dúvida sobre a eficácia do argumento de um produto "ecologicamente correto" tenha uma vantagem competitiva.

Tabela 3: Nível de utilidade dos atributos de inseticida (\%)

\begin{tabular}{|c|c|c|c|c|c|c|}
\hline INSETICIDA & Cheiro & Biodegradabilidade & Preço & Marca & $\begin{array}{c}\text { Bio } \\
\text { (Sim) }\end{array}$ & $\begin{array}{c}\text { Bio } \\
\text { (Não) }\end{array}$ \\
\hline Amostra (39) & 19 & $\mathbf{3 0}$ & $\mathbf{3 0}$ & 21 & $\mathbf{1 , 0}$ & 0,0 \\
\hline Mulheres (18) & 2 & $\mathbf{4 2}$ & 36 & 20 & $\mathbf{1 , 0}$ & 0,0 \\
\hline Homens (21) & $\mathbf{2 7}$ & 24 & $\mathbf{2 7}$ & 22 & $\mathbf{0 , 9 3}$ & 0,06 \\
\hline $\begin{array}{c}\text { Educação Superior } \\
\text { (28) }\end{array}$ & 22 & $\mathbf{3 8}$ & 15 & 26 & $\mathbf{1 , 0}$ & 0,0 \\
\hline $\begin{array}{c}\text { Edução Inferior } \\
\text { (11) }\end{array}$ & 13 & 14 & $\mathbf{6 1}$ & 13 & $\mathbf{0 , 6 1}$ & 0,39 \\
\hline Renda Alta (16) & 27 & $\mathbf{3 2}$ & 13 & 27 & $\mathbf{1 , 0}$ & 0,0 \\
\hline Renda Baixa (16) & 12 & 24 & $\mathbf{5 0}$ & 14 & $\mathbf{0 , 7 5}$ & 0,27 \\
\hline
\end{tabular}

Um novo experimento teve início em 2004, com apoio no interesse de explorar o conceito de "jóia ecológica". O método aplicado foi o mesmo descrito para os outros produtos. Analisou-se o valor atribuído

Uma análise segmentada por gênero mostra que mulheres valorizam mais a biodegradabilidade (42\%) do que homens, enquanto eles se mostram mais sensíveis a preço $(27 \%)$ e cheiro $(27 \%)$. Uma análise com base no grau de instrução mostra o mesmo resultado encontrado no experimento com detergentes: respondentes com grau de instrução superior valorizam mais a biodegradabilidade (38\%), enquanto os de grau de instrução inferior se mostram mais sensíveis a preço (61\%). Esse resultado parece estar também relacionado com a renda familiar, conforme pode ser observado nas últimas duas linhas da Tabela 3. Contudo, a lógica existente por trás desses resultados pode estar mais relacionada à preocupação das pessoas com o seu bem-estar ou o de seus familiares do que com o meio ambiente.

Conversas realizadas com os participantes após o experimento oferecem uma possível explicação para suas escolhas. Ao usar o produto, o ar do ambiente é "contaminado" pelos ingredientes de sua fórmula. É dentro desse ambiente protegido dos insetos que as pessoas vão

\begin{tabular}{|c|c|c|c|c|c|c|c|c|}
\hline JÓIAS & Estilo & $\begin{array}{l}\text { Tipo de } \\
\text { Material }\end{array}$ & Preço & Design & $\begin{array}{l}\text { Materiais } \\
\text { Nobres e } \\
\text { Ecológicos }\end{array}$ & $\begin{array}{l}\text { Materiais } \\
\text { Nobres }\end{array}$ & $\begin{array}{l}\text { Materiais } \\
\text { Alternativos }\end{array}$ & $\begin{array}{l}\text { Materiais } \\
\text { Ecológicos }\end{array}$ \\
\hline $\begin{array}{l}\text { Amostra } \\
(28)\end{array}$ & 5,4 & 44,3 & 49,6 & 0,8 & 0,6 & 1,0 & 0,2 & 0,2 \\
\hline Homens (6) & 2,4 & 53,4 & 44,0 & 0,3 & 0,4 & 1,0 & 0,0 & 0,2 \\
\hline $\begin{array}{l}\text { Mulheres } \\
\text { (22) }\end{array}$ & 6,5 & 42,6 & 49,8 & 1,1 & 0,6 & 1,0 & 0,3 & 0,2 \\
\hline
\end{tabular}
respirar. A percepção de que haja uma fórmula menos danosa ao "consumo humano", aqui descrita como por compradores de jóias àqueles feitos com materiais ecológicos, em comparação aos chamados materiais tradicionais ou "nobres", tais como ouro e prata.

A coleta de dados se deu, majoritariamente, em ambientes de compra de jóias, embora feita com base nos cartões de simulação. Os cartões apresentavam as imagens das peças selecionadas e traziam as descrições de suas composições. A amostra foi de apenas 28 pessoas, sendo $80 \%$ composta de mulheres e $20 \%$ de homens.

As variáveis e níveis escolhidos foram: tipo de material (nobre ou convencional, ecológico, nobre com ecológico e alternativo); designer (com assinatura ou sem assinatura de autoria); preço (promocional, regular, alto, luxury); estilo (clássico ou moderno). Produtos ecológicos foram definidos por terem madeira certificada ou reciclada. Materiais alternativos foram definidos como sintéticos e acrílicos, entre outros. Os resultados referentes aos pesos dos quatro atributos selecionados e os níveis de utilidade dos quatro tipos de material são resumidos na Tabela 4. 
produção das peças $(44,3 \%)$. Entre os diferentes tipos de material, o de maior valor percebido foi o nobre (ou convencional), com $100 \%$ de percepção de utilidade. Os menos considerados foram estilo $(5,4 \%)$ e assinatura de um designer $(0,8 \%)$.

Esses resultados não foram surpreendentes, uma vez que o conceito de produto ecológico na indústria de jóias representa uma novidade ainda em desenvolvimento. Emboraautilidadepercebidadosmateriaisecológicostenha sido muito baixa $(0,2)$, ela se mostra consideravelmente maior quando associada aos materiais nobres $(0,6)$, o que sugere uma oportunidade para os ecodesigners. No entanto, a percepção de valor de jóias com materiais ecológicos, quando somados aos convencionais, parece ser um pouco mais relacionada às mulheres do que aos homens $(0,6$ universitárias de Administração e usuárias deste tipo de cosmético, serviu para testar os níveis identificados no campo. A simulação inicial considerou um tipo especial de creme para o rosto, cujos valores eram relativamente elevados. Posteriormente um tipo de creme mais popular foi selecionado para facilitar a busca de dados no campo. As diferenças mais significantes no perfil da amostra são a renda familiar, a idade e o status marital. Os atributos e níveis analisados neste estudo foram: ingrediente (natural ou químico); embalagem (tipo pote ou bisnaga); preço (R\$5.00, R\$9.00, R\$10.00, R\$15.00); marca (Natura, Nívea, Avon, L'Oreal). Os resultados dos pesos das quatro variáveis e dos dois níveis de utilidade dos ingredientes são resumidos na Tabela 5 .

e 0,4 respectivamente).

Embora ambos valorizem sobremaneira os materiais nobres $(1,0)$, as mulheres se mostraram mais sensíveis a preço, enquanto os homens a aos materiais. Este último parece mais conservador em relação às suas escolhas de jóias

Tabela 5: Nível de utilidade dos atributos de creme hidratante (\%)

\begin{tabular}{|c|c|c|c|c|c|c|}
\hline $\begin{array}{c}\text { CREME } \\
\text { HIDRATANTE }\end{array}$ & Ingrediente & Embalagem & Preço & Marca & $\begin{array}{c}\text { Ingredientes } \\
\text { Naturais }\end{array}$ & $\begin{array}{c}\text { Ingredientes } \\
\text { Químicos }\end{array}$ \\
\hline Mulheres (84) & $\mathbf{4 8 , 2}$ & 0,5 & 12,9 & 38,4 & $\mathbf{1 , 0}$ & 0,0 \\
\hline $\begin{array}{c}\text { Idade até 25 anos } \\
(44)\end{array}$ & $\mathbf{4 4 , 2}$ & 2,7 & 14,2 & 39,0 & $\mathbf{1 , 0}$ & 0,6 \\
\hline $\begin{array}{c}\text { De 26 a 30 anos } \\
\text { (11) }\end{array}$ & $\mathbf{4 4 , 8}$ & 8,6 & 17,7 & 28,9 & $\mathbf{1 , 0}$ & 0,0 \\
\hline $\begin{array}{c}\text { De 31 a 40 anos } \\
\text { (21) }\end{array}$ & $\mathbf{4 7 , 6}$ & 0,5 & 10,2 & 41,7 & $\mathbf{1 , 0}$ & 0,0 \\
\hline $\begin{array}{c}\text { Acima de 40 anos } \\
\text { (6) }\end{array}$ & $\mathbf{5 6 , 5}$ & 5,6 & 11,0 & 26,9 & $\mathbf{1 , 0}$ & 0,0 \\
\hline Renda Média (29) & $\mathbf{4 5 , 4}$ & 8,3 & 16,3 & 30,0 & $\mathbf{1 , 0}$ & 0,0 \\
\hline Renda Alta (27) & $\mathbf{5 1 , 8}$ & 0,3 & 5,7 & 42,2 & $\mathbf{1 , 0}$ & 0,0 \\
\hline
\end{tabular}

e provavelmente menos

aberto à ideia de que materiais ecológicos possam ser valorizados nesse tipo de produto.

Outros produtos foram incluídos na pesquisa em 2006, 2007 e 2008, de modo a ampliar o número de tipos de produtos, formas de consumo, faixas de preço e tipo de apelo ecológico. Analisou-se creme hidratante de corpo, pneus, artigos de decoração, pilhas e cadernos, sob a ótica do valor atribuído a variáveis como ingredientes naturais, materiais reciclados, madeira certificada, capacidade de recarga, entre outras. Esses níveis foram comparados a outros "não ecológicos", assim como a diferentes marcas, preços e embalagens.

\section{Creme hidratante}

A pesquisa envolvendo o creme hidratante de corpo começou em 2006 e continua em desenvolvimento. Usou-se uma amostra inicial para identificar os atributos mais relevantes do produto com base em conversas com consumidoras experientes. Uma segunda amostra, composta de 22 mulheres jovens, estudantes
A amostra é composta totalmente de mulheres e totalizam 84 consumidoras compradoras regulares do produto. A relevância do tipo de ingrediente é unânime entre todos os subgrupos e parece crescer com a idade e a renda familiar das respondentes. É também unânime a preferência pelos ingredientes naturais e a grande aversão aos ingredientes químicos. Algumas explicações extraídas dos relatos das participantes são listadas abaixo.

"Eu gosto de produtos naturais porque minha pele é sensivel a ingredientes químicos e podem me causar alguma reação alérgica”;

"Se o produto é natural, eu penso que é mais dificil ter algum efeito colateral",

"Os produtos naturais são mais benéficos para a minha saúde”,

"Os ingredientes naturais são menos agressivos ao ambiente e menos danosos à pele porque são mais naturais, menos químicos";

"No caso de produtos com contato direto com meu corpo, eu prefiro produtos com bases naturais"; 


"A despeito de serem
produtos mais caros,
eu penso que são mais
saudáveis para minha
pele".

Observa-se que a preocupação central dessas consumidoras é com a saúde de sua pele. Embora haja menção ao aspecto benéfico dos ingredientes naturais ao meio ambiente nos questionários, uma associação complementar é feita com relação ao dano à pele da consumidora. Com base nos dados extraídos dos questionários e nos resultados da simulação, pode-se concluir que os ingredientes naturais são muito relevantes no processo de escolha de cremes hidratantes e a razão maior para a sua escolha não é a preocupação com o meio ambiente, conforme seria de supor inicialmente, mas com o bem-estar de quem compra.

\section{Pneus}

A pesquisa envolvendo pneus começou em 2006 e também se encontra em fase de desenvolvimento. Uma amostra inicial foi usada para testar o experimento com atributos coletados no campo, totalizando 22 jovens consumidores, todos do sexo masculino e estudantes de Administração de Empresas. Depois a amostra foi aumentada para 71 pessoas, sendo todos proprietários de carros e estudantes de curso superior, tanto de graduação como de pós-graduação, em duas instituições distintas da cidade do Rio de Janeiro. As mais significantes diferenças entre os perfis dos respondentes foram renda, idade e status marital. Os atributos e níveis analisados foram: processo de produção (original ou remoldado); estilo (esportivo e tradicional); marca (BS Colway, Goodrich, Continental, Pirelli); preço (R\$120.00, R\$210.00, $\mathrm{R} \$ 264.00, \mathrm{R} \$ 307.00)$. Os resultados são resumidos na Tabela 6. Os dois níveis de utilidade de interesse são referentes aos tipos de produção original e o remoldado (ou ecológico).

Os dados mostram que preço (38\%) e marca $(35 \%)$ são as variáveis mais relevantes entre as selecionadas e que o tipo de produção é considerado apenas o terceiro fator de importância $(18,4 \%)$.
Uma análise específica sobre as duas alternativas de produção (original ou remoldado) mostra que todos os subgrupos preferem o original $(0,79)$ e avaliam de forma mais baixa a opção do remoldado $(0,32)$. Observa-se que há um declínio na percepção de valor dessa característica de apelo ecológico com o aumento de renda e idade. Alguns argumentos a este respeito foram expostos nos questionários e ajudam a entender a lógica dos respondentes: há uma forte aversão ao produto remoldado por descrença de sua qualidade e receio de sua segurança. Alguns desses comentários são apresentados abaixo.

"A tendência do mercado é não agredir a natureza, mas eu opto pela qualidade do produto em primeiro lugar, sem considerar essa variável (ecológica)”; "Atualmente os fabricantes usam o apelo ecológico apenas como forma de propaganda";

"O descarte no meio ambiente é importante. No entanto, como a segurança é uma parte importante do produto e de minha família (e minha), o fato de ser reciclado não pesa muito na minha escolha”;

"Eu prefiro algo que me dê confiança no produto. Depois eu considero a durabilidade e o preço. Somente depois dessas considerações eu vejo se o produto é ecologicamente correto ou não”;

"A performance dos pneus remoldados é menor do que os novos";

"Eu não me sinto seguro com pneus reciclados";

"Eu nunca compro pneus remoldados. Estamos falando de minha vida (segurança) e isso está diretamente relacionado com a qualidade do produto".

Além desses comentários, outras observações feitas confirmam a percepção negativa dos respondentes em relação aos pneus remoldados, a despeito do seu apelo ecológico. De fato, muitos respondentes manifestaram ceticismo em relação à qualidade do 
pneu reciclado. Os valores atribuídos aos tipos "original" e "remoldado" revelam essa percepção. Como os produtos não transmitem segurança a vários desses compradores, pode-se concluir que seu conceito precisa ser melhor defendido pelos produtores diante da opinião pública, caso seja realmente possível comprovar seus méritos em relação a durabilidade e segurança. Contudo, a percepção de valor desse conceito parece estar associada com maior frequência ao público mais jovem, possivelmente porque os apelos ecológicos estão mais presentes nas ofertas mais recentes. Esse dado pode sugerir uma mudança na percepção de valor desse argumento no futuro. Visto que marca e preço se mostraram duas variáveis muito valorizadas no processo decisório de escolha de pneus, é possível supor que a prática da reciclagem por parte dos fabricantes com marcas renomadas e o suporte de algum tipo de política de preço promocional favoreçam a adoção de pneus remoldados pelos novos compradores.

\section{Artigos de decoração}

Conduziu-se uma pesquisa, em 2008, para identificar o valor de características ecológicas em artigos de decoração para o lar. Esse trabalho foi motivado por uma nova tendência no ramo moveleiro: a produção de peças de madeira ou certificada ou reciclada. Nesse caso, não foi selecionado um item apenas, mas um conjunto de diferentes peças. Os quatro atributos selecionados e seus níveis foram definidos com base na natureza das produções dos itens. Foram eles: tipo de material (reciclado/ reutilizado ou novo); estilo (moderno/contemporâneo ou rústico); processo produtivo (artesanal, artesanal com assinatura de um designer conhecido, industrial, industrializado com assinatura de um designer conhecido); preços (promocional, abaixo da média, acima da média, premium). A amostra constituiu-se de 31 pessoas, e os dados foram coletados em três diferentes pontos de venda, todos com ofertas desses tipos de produtos. Dessa amostra, $87 \%$ foi composta por mulheres, o que impediu qualquer avaliação por gênero. Ainda, devido ao extenso tempo de coleta dos dados no campo, foi utilizada uma versão mais resumida do questionário, restringindo a possibilidade de análises por segmentos. Os resultados agregados são mostrados abaixo(Tabela 7).
$\mathrm{O}$ atributo com o maior peso no procedimento de escolha dos produtos foi o processo produtivo (40\%), seguido por preço $(34,8 \%)$, tipo de material $(16,7 \%)$ e estilo $(8,6 \%)$. Entre as alternativas disponíveis, o modo de produção "artesanal com assinatura de um designer" foi o mais cotado, seguido do "industrial com assinatura de um designer". Esse resultado indica a valorização do designer na escolha de peças de decoração. De certa forma ele era esperado, uma vez que as lojas selecionadas eram especializadas em peças de artistas conhecidos e com alguma influência ecológica.

O tipo de material foi a terceira variável mais valorizada, com preferência para o tipo "reciclado", resultado também não de todo surpreendente, dado o posicionamento das lojas onde os respondentes foram abordados. No entanto, apenas 11 dos consumidores entrevistados perceberam no estilo "rústico" algo relacionado ao ecológico ou a um menor dano ao meio ambiente. Da mesma forma, apenas cinco dos respondentes revelaram explicitamente levar em conta qualquer característica ambiental no seu processo de escolha. O estilo, por si só, ou o seu apelo visual parecem ter um peso maior nesse momento. Portanto, os comentários trazem dúvidas sobre a real importância dos fatores ecológicos nas suas decisões de compra de peças de decoração.

\section{Cadernos}

Esta pesquisa começou em 2008 e ainda está no seu estágio inicial. $\mathrm{O}$ interesse pelo produto tem origem na oferta de cadernos com folhas recicladas e sua fácil adoção por parte do público universitário, alvo de pesquisas anteriores. Os atributos e os níveis identificados como relevantes para o experimento foram: capa (decorada ou não decorada); tipo de papel (reciclado ou não); preço (R $\$ 7.90, \mathrm{R} \$ 9.90, \mathrm{R} \$ 12.90, \mathrm{R} \$ 15.90)$; marca (Nova Grafon, Tilibra, Cadersil e Foroni). O caderno universitário com 96 folhas foi utilizado como objeto específico no experimento. Os primeiros resultados, com uma amostra de 33 respondentes, todos estudantes universitários, são apresentados na Tabela 8.

Os dados agregados mostram um maior envolvimento da amostra com a marca $(40.7 \%)$ e revelam também uma 
considerável sensibilidade a preço (38.7\%) na compra desse tipo de produto. A variável de maior interesse no estudo, o tipo de papel, apareceu como um atributo muito pouco relevante, com apenas $0,6 \%$ do peso decisório.

Esse resultado é surpreendente, em particular pelo fato de estar fortemente ligado a um público de formação superior e pertencente a uma classe social elevada. Também surpreendente é o fato de os respondentes do sexo masculino perceberem maior valor no papel reciclado do que as mulheres. Ainda, embora o tipo de papel seja o segundo atributo com maior peso no processo de escolha desse público, o que se observa é uma forte rejeição ao tipo reciclado. Como a grande maioria dos participantes reconheceu nos questionários a relação entre o papel reciclado e sua contribuição para a manutenção do meio ambiente, o resultado contrasta com a atitude do público feminino verificada nos experimentos realizados até então. As razões não são claras ainda, surgindo apenas algumas considerações negativas sobre a cor do papel e a ausência de personagens ou estampas no tipo reciclado, o que requer outros estudos sobre o produto.

Tabela 8: Nível de utilidade dos atributos de cadernos (\%)

\begin{tabular}{|c|c|c|c|c|c|c|}
\hline CADERNOS & Capa & $\begin{array}{c}\text { Tipo de } \\
\text { papel }\end{array}$ & Preço & Marca & $\begin{array}{c}\text { Papel } \\
\text { Reciclado }\end{array}$ & $\begin{array}{c}\text { Não } \\
\text { Reciclado }\end{array}$ \\
\hline $\begin{array}{c}\text { Amostra } \\
(33)\end{array}$ & 20,0 & 0,6 & $\mathbf{3 8 , 7}$ & $\mathbf{4 0 , 7}$ & $\mathbf{0 , 4 1}$ & $\mathbf{0 , 4 3}$ \\
\hline $\begin{array}{c}\text { Homens } \\
(19)\end{array}$ & 26,0 & 10,8 & $\mathbf{3 5 , 6}$ & 27,5 & $\mathbf{0 , 6 4}$ & 0,35 \\
\hline $\begin{array}{c}\text { Mulheres } \\
(14)\end{array}$ & 9,7 & 30,0 & 18,4 & $\mathbf{4 1 , 9}$ & 0,0 & $\mathbf{0 , 7 2}$ \\
\hline
\end{tabular}

\section{Pilhas}

Esta pesquisa também se encontra em um estágio inicial. A motivação para a escolha do produto está no fato de pilhas recarregáveis reduzirem um tipo de lixo muito danoso ao meio ambiente. As variáveis identificadas como relevantes na pesquisa de campo foram: tipo de carga (recarregável ou descartável); tipo de material (lítio ou níquel); preço ( $\mathrm{R} \$ 3.00, \mathrm{R} \$ 4.00, \mathrm{R} \$ 15.00, \mathrm{R} \$ 20.00)$; marca (Duracell, Rayovac, GP, Sony). Até o momento foram entrevistadas 21 pessoas, $95 \%$ do sexo masculino, todas estudantes de um curso universitário. Devido ao tamanho ainda reduzido da amostra não foi possível fazer comparações em relação a gênero, classe social ou nível de instrução, entre outras variáveis. Os primeiros resultados são apresentados na Tabela 9.

Tabela 9: Nível de utilidade dos atributos de pilhas (\%)

\begin{tabular}{|c|c|c|c|c|c|} 
Carga & Material & Preço & Marca & $\begin{array}{c}\text { Pilha } \\
\text { Recarregável }\end{array}$ & $\begin{array}{c}\text { Não } \\
\text { Recarregável }\end{array}$ \\
\hline 11,5 & 2,6 & $\mathbf{4 6 , 9}$ & 39,0 & $\mathbf{0 , 6 5}$ & $\mathbf{0 , 4 1}$ \\
\hline
\end{tabular}

Os dados até agora sugerem uma forte influência do preço e da marca na escolha da compra do produto. De fato, a diferença entre os preços das pilhas descartáveis e recarregáveis é considerável. Embora se perceba uma maior valorização do tipo recarregável $(0,65)$, relatos dos respondentes indicam que o interesse por ele se dá mais pela conveniência de não obrigá-los a recomprar o produto sistematicamente. Outros comentários revelam que o valor da pilha recarregável é também explicado pelo seu valor econômico, já que ela pode ser reutilizada várias vezes. Pouco foi dito nos questionários sobre a contribuição desse atributo para a sustentabilidade do meio ambiente, embora seja reconhecido que a possibilidade da recarga esteja relacionada a um benefício a ele.

\section{ANÁLISES E CONCLUSÕES}

Mensurar o efeito de uma variável sobre o processo de escolha de consumidores é uma tarefa difícil, cujas conclusões requerem alguns cuidados. Contudo, após dez anos de estudos, analisando sentimentos, crenças, intenções de compra e consumo de diferentes tipos de produtos com apelos ecológicos, alguns resultados se mostram recorrentes, os quais permitem algumas conclusões.

O principal objetivo proposto neste trabalho foi identificar o valor percebido por consumidores em relação às características ecológicas de produtos, quando comparadas com outras variáveis também importantes no seu processo decisório de compra. Definindo produtos ecológicos como aqueles que portam características como a reciclabilidade, a possibilidade de reutilização, a produção com material reciclado ou com ingredientes naturais, entre outras, observa-se que o valor atribuído a elas varia de acordo com o tipo de produto. Contudo, talvez seja mais preciso e cuidadoso afirmar que, considerando os atributos e os níveis testados nos experimentos, um atributo ou outro é mais valorizado ou preferido pelo consumidor se consideradas apenas as 
opções selecionadas no estudo (CURRY, 1997). Tendo isso em mente podem-se fazer outras considerações.

Os experimentos trabalhados com inseticidas, cremes hidratantes para o corpo e pneus, revelaram um peso maior da variável ecológica no processo de escolha dos consumidores. Contudo, não na mesma direção. Embora no caso dos inseticidas e cremes hidratantes a característica ecológica seja considerada positiva, no caso dos pneus ela é fortemente negativa, isto é, o fato de o pneu ser remoldado parece gerar uma atitude negativa por parte da amostra analisada. Esse resultado sugere a necessidade de um trabalho mais profundo das áreas de pesquisa e comunicação dessas empresas para confirmar a percepção dos seus consumidores em relação aos benefícios do produto e, consequentemente, identificar novas formas de promovê-los. Por outro lado, os comentários feitos pelos entrevistados em relação aos inseticidas e cremes hidratantes, os quais traduzem de alguma forma suas atitudes, revelam que embora sejam favoráveis ao meio ambiente, ou sensíveis ao apelo ecológico, as razões por trás de suas escolhas recaem ou sobre a sensação de segurança ou sobre a preocupação com o seu bem-estar e sua saúde. A ausência de percepção de segurança nos pneus remoldados também explica o resultado negativo. Dessa forma, pode-se propor que a valorização das variáveis ecológicas nem sempre pode estar relacionada ao seu impacto sobre o meio ambiente, mas aos benefícios complementares que causam aos próprios consumidores.

Os estudos realizados com os demais produtos não revelaram um valor consideravelmente elevado das variáveis ecológicas frente às outras selecionadas. Os indícios de valor encontrados nos estudos com ovos embalados, detergentes, artigos de decoração e pilhas são explicados pelos respondentes como não relacionados diretamente à preocupação com o meio ambiente. Os estudos realizados com jóias e cadernos mostram um baixo valor das características ecológicas.

O segundo objetivo do trabalho foi identificar quais características dos produtos e consumidores estão mais relacionados à percepção de valor das variáveis ecológicas. Os resultados obtidos sugerem que consumidores percebem mais diretamente o efeito (valor) dos atributos ecológicos quando o consumo dos produtos em questão têm impactos mais notáveis sobre sua saúde, seu corpo, ou afetam sua percepção de segurança, tais como inseticidas, cosméticos e pneus. Nos casos dos produtos cujas características ecológicas foram identificadas como de baixo valor, em particular jóias e cadernos, as razões encontradas se referem à inadequação do material ecológico ao tipo de produto. No caso das jóias, o conceito de ecológico parece não estar associado ao conceito de jóia. No caso dos cadernos com papéis reciclados, o aspecto visual parece ofuscar o valor do benefício ao meio ambiente. De um modo geral, os comentários feitos nos questionários e que complementaram as análises quantitativas realizadas nos experimentos apresentados neste trabalho, dão suporte à proposição de que os consumidores nem sempre fazem suas escolhas com base nos benefícios ambientais, mas, sim, em suas próprias expectativas e seus benefícios pessoais.

Esse tipo de comportamento reflete uma visão mais individualista dos consumidores, conforme identificado por Portney (1997) e Hart (1997). Segundo esses autores, a preocupação é maior com o benefício que o produto traz para o consumidor em si e não necessariamente com o benefício que possa oferecer ao meio ambiente. Se consumidores percebem que o produto é bom para eles próprios, e também para o meio ambiente, então eles podem ter a inclinação para a escolha do produto "verde" ou ecológico. Uma pilha recarregável, por exemplo, pode ser preferível a uma descartável por ser mais conveniente e não ter de ser comprada sistematicamente. Se for também benéfica ao meio ambiente, melhor. Isto é, acima de tudo o produto precisa ser percebido como competitivo e satisfatório por si só. Se, além disso, tiver como característica complementar o fato de ser ecologicamente, melhor. Ottman $(1994 ; 2007)$ sugere a mesma linha de ação, que parece ser a abordagem promocional mais recomendável para gestores de marketing que lidam com esses produtos.

De um modo geral, os resultados indicam que as mulheres têm uma preocupação maior em relação ao meio ambiente e valorizam mais as variáveis ecológicas nos processos de escolha. Esse foi o resultado encontrado em praticamente todos os experimentos realizados com análise segmentada por gênero: ovos, detergentes, inseticidas, jóias e creme hidratante. $\mathrm{O}$ resultado encontrado no experimento realizado com cadernos, no 
entanto, revela uma exceção. Nesse caso, em particular, há claros sinais de rejeição aos papéis reciclados por parte desse público. Novos estudos serão necessários para confirmar esse resultado e, em caso positivo, identificar as suas razões. Os primeiros indícios apontam para uma aversão à cor do papel reciclado e também para a objeção à falta de personagens, de imagens coloridas e de enfeites no tipo de papel, temas que podem ser melhor trabalhados por gerentes de marketing do setor.

Há também sinais de que consumidores com nível de instrução superior e renda superior são mais propensos a valorizar os produtos ecológicos. Esses resultados podem ser identificados nos estudos que incluíram essas variáveis, tais como ovos, detergentes, inseticidas e cremes hidratantes. Em menor escala, também, nos casos de jóias e artigos de decoração. Há, contudo, uma exceção. A pesquisa com pneus remoldados mostrou uma menor aversão ao produto por parte da amostra com menor renda. É possível, portanto, que uma campanha promocional que enfatize os atributos de segurança do produto e os seus preços mais reduzidos, em comparação aos pneus originais, venha a apresentar bons resultados com esse público em especial.

Foram poucos os experimentos cujas amostram permitiram uma análise por faixa etária: cremes hidratantes e pneus. No caso dos cremes, há indicação de que mulheres com faixa etária superior valorizam mais os ingredientes naturais do que os químicos. Contudo, não se pode concluir se a preferência está mais relacionada ao meio ambiente, ao seu apelo ecológico ou ao benefício da pele. No caso dos pneus, os indícios são menos claros, mas apontam para uma maior aversão ao produto remoldado por parte do público mais velho.

Por fim, o trabalho buscou avaliar até que ponto as alegadas atitudes em prol dos produtos ecológicos são coerentes com as escolhas dos consumidores. Nesse sentido, pode-se dizer que o Modelo de Construção de Comportamento de Engel et al. (2000) não respondeu inteiramente à lógica das escolhas dos consumidores pesquisados. Com base naquele modelo, uma atitude favorável leva a uma propensão também favorável para a escolha ou o consumo de determinado objeto. $\mathrm{O}$ que se observou nos experimentos foi certo grau de contradição, uma vez que muitas das manifestações favoráveis ao meio ambiente e das alegações favoráveis feitas pelos respondentes nos questionários não se revelaram compatíveis com a hierarquia das escolhas feitas durante as simulações. Contradições também foram encontradas nos trabalhos de Wagner (1997), Mainieri et al. (1997), Marques (1998), Lages e Neto (2002), Rocha e Marques (2004).

Cornelissen at al. (2008) sugerem que em algumas situações "fazer o que os outros fazem pode ser preferível a fazer o que é certo" (p. 54), embora Cornelissen et al. (2007) defendam que consumidores procuram atender seus próprios objetivos. Nessa argumentação, o segmento de mercado que define o público ecologicamente mais consciente ou correto tenderá a ser mais consistente e coerenteaolongodotempo, umavezqueo "ecologicamente correto" se identifica com o seu conceito do que é certo ou preferível. Até aqui os resultados apontam para o público feminino em especial, embora haja espaço para supor que uma definição mais precisa desse público-alvo se faça necessária, considerando diferentes tipos de produtos.

Embora seja possível que a falta de fidedignidade dos respondentes nestes estudos tenha afetado os resultados, assim como a restrição a apenas quatro variáveis na simulação e as circunstâncias nas quais foram realizadas, é razoável supor que em muitos casos as pessoas de fato não fazem sempre aquilo que pensam, ou seja, não agem de acordo com suas próprias intenções. Conveniências, restrições orçamentárias ou mesmo a ausência de produtos compatíveis com suas reais demandas podem explicar tais condutas.

Os sinais de contradição identificados entre as opiniões e os sentimentos declarados em relação ao meio ambiente e aos produtos ecológicos (atitudes), e entre as escolhas feitas pelos respondentes em relação a alguns dos produtos aqui classificados como ecológicos, grande parte encontrados nos experimentos relatados, não diferem muito daqueles encontrados em trabalhos passados. Contudo, essa observação é mais clara em alguns grupos de consumidores do que em outros. As análises feitas em relação à influência do gênero, do nível de educação e renda sobre a preferência por ofertas ecológicas indicam que compradores do sexo feminino, de nível de instrução e renda superiores, são mais coerentes nesse aspecto.

Contudo, há outra possível explicação para tais resultados. Foi identificado certo ceticismo por parte dos respondentes em relação aos apelos ecológicos 
feitos pelas empresas em geral e seus benefícios. Esse resultado também foi encontrado por Johansson (1998). Em várias ocasiões, os respondentes afirmam não confiar nas empresas que produzem ou promovem produtos ditos ecologicamente corretos. De fato, em alguns países selos certificadores dão credibilidade a esses tipos de produtos, pois atestam, por meios independentes, os reais atributos ecológicos dos produtos certificados. São os chamados selos verdes ou ecológicos. Embora o Brasil tenha selos dessa natureza pelo menos há uma década, aparentemente são pouco explorados pelas empresas ou pouco percebidos pelos compradores. As razões para tal merecem maiores estudos.

Uma sugestão resultante da análise dos estudos aqui realizados pode ser dirigida aos gerentes de marketing das empresas com preocupações ecológicas ou que comercializam produtos com características ecológicas. É necessária uma comunicação mais transparente em relação às suas ofertas, informando detalhes sobre a composição dos seus produtos, o método produtivo e os cuidados com seu descarte pós-consumo. Detalhes esses que relacionem os atributos dos produtos e os seus benefícios para os consumidores e também para o meio ambiente, já que há indícios de que muitas vezes, antes de pensar no coletivo, o comprador ou consumidor procura satisfazer suas necessidades. Nesse ponto de vista, produtos com apelos ecológicos devem ser caracterizados por ofertas diferenciadas, que vão além da satisfação funcional e emocional do consumidor, sem deixar de fazê-lo, mas que também contribuam para a redução dos problemas ambientais. Essa deve ser na prática a promessa e a entrega do chamado marketing ambiental.

\section{REFERÊNCIAS}

ALMEIDA, G. S., NASCIMENTO Jr., A.; PASTORE, E. M. Ambientalismo e cultura de consumo: um estudo do consumidor do Distrito Federal. IX ENGEMA - Encontro Nacional Sobre Gestão Empresarial e Meio Ambiente, 2007, Curitiba. In: Anais..., Curitiba, 2007.

ASHLEY, P. A. - Tendências do "dever-ser" quanto ao comércio ético de alimentos na gestão estratégica de supermercados a partir da práxis coletiva pesquisador-ASSERJ-ABRAS. Tese de doutorado, Departamento de Administração. Orientadora: T. Diana de L. V. A. de Macedo-Soares. Pontifícia Universidade Católica do Rio de Janeiro, 2002.

AZEVÊDO, A. C. de; GALÃO, F. P.; BACCARO, T. A. - $A$ Pesquisa na Área do Comportamento do Consumidor no Marketing Ambiental: Uma Revisão da Produção Acadêmica
Brasileira Entre 1994 e 2007. Disponível em http://www.ead. fea.usp/semead/11semead/trabalhosPDF/725.pdf, acessado em 03 de agosto de 2009.

BAISCH, L. B. - Marketing Verde e o Consumo Consciente: Um Estudo Sobre o Apelo Ecológico de dois Produtos, Dissertação de Mestrado, Departamento de Administração, Pontifícia Universidade Católica do Rio de Janeiro, 2008

BANSAL, P.; ROTH, K. - Why Companies Go Green: A Model of Ecological responsiveness. The Academy of Management Journal, vol. 43 (4), Aug. 2000, p. 717-736.

BEDANTE, G. N.; SLONGO, L. A. - O Comportamento de Consumo Sustentável e suas Relações com a Consciência Ambiental e a Intenção de Compra de Produtos Ecologicamente Embalados. Encontro de Marketing (EMA). In: Anais... Atibaia (SP): ANPAD, 2004.

CASTRO, G. V. de - Design de Interiores e Consumo: A Percepção dos Aspectos Sócio-Ambientais em Móveis e Objetos Decorativos. Dissertação de Mestrado, Departamento de Artes e Design, Pontifícia Universidade Católica do Rio de Janeiro,

CHEN, C. - Design for the Environment: A Quality-Based Model for Green Product Development. Management Science, vol. 47, n 2, Feb. 2001, p. 250-263.

CHEUNG, S. M. S. - The Fable of the Bees: An Economic Investigation. Journal of Law and Economics, The University of Chicago Press, n. 16, 1973, p. 11-33.

COASE, R. H. - The Problem of Social Cost. Journal of Law and Economics, The University of Chicago Press, n. 3, 1960, p. 11-44.

COHN, D. Y.; SHERMAN, E.; SCHIFFMAN, L. G. - An Examination of a Firm-Level Model of Green Marketing Strategies. GBATA's Eleventh Annual International Conference, July 7-11, Prague, 2009. In: Readings Book... GBATA, 2009.

CORNELISSEN, G.; DEWITTE, S.; WARLOP, L.; YZERBYT, V. - Whatever people say I am, that's what I am: Social labeling as a social marketing tool. International Journal of Research in Marketing, vol. 24, 2007, p. 278-288.

CORNELISSEN, G.; PANDELAERE, M.; WARLOP, L.; DEWITTE, S. - Positive cueing: Promoting sustainable consumer behavior by cueing common environmental behaviors as environmental. International Journal of Research in Marketing, vol. 25, 2008, p. 46-55.

CRESPO, S.; LEITÃO, P. - O que o brasileiro pensa da ecologia. Rio de Janeiro: MAST/CETEM/AGÊNCIAESTADO/ ISER, 1993.

CURRY, J. - After the basics: keeping key issues in mind makes conjoint analysis easier to apply. Marketing Research Forum, Spring, 1997, p. 6-11.

DOBSON, A. - Green political thought: An introduction. London: Unwin Hyman, 1990.

ELKINGTON, J.; HAILES, J.; MAKOWER, J. - The Green Consumer, New York: Penguin, 1990

ENGEL, J. F.; BLACKWELL, R. D.; MINIARD, P. W. Comportamento do Consumidor. 8 ed. Rio de Janeiro: Livros Técnicos e Científicos Editora S.A., 2000. 
FAGGIANI, K. C. C. - Jóia Contemporânea: Aspectos Ecológicos e a Percepção do Consumidor. Dissertação de Mestrado, Departamento de Artes e Design, Pontifícia Universidade Católica do Rio de Janeiro, 2005.

FRANÇOIS, P.; MacLACHLAN, D. L. - Ecological validation of alternative customer-based brand strength measures. International Journal of Research in Marketing, vol. 12, 1995, p. 321-332.

GONÇALVES-DIAS, S. L. F.; MOURA, C. - Consumo Sustentável: Muito Além do Consumo "Verde". XXXI Encontro Nacional da ANPAD. Rio de Janeiro, 22 a 26 de setembro de 2007. In: Anais... Rio de Janeiro, 2007.

GONZAGA, C. A. M. - Marketing Verde de Produtos Florestais: Teoria de Prática. Floresta. Curitiba, PR, v. 35, n. 2, maio/ agosto, 2005, p. 353-368.

GREEN, P. E.; SRINIVASAN, V. - Conjoint Analysis in Marketing: New Development with Implication for Research and Practice. Journal of Marketing, Oct. 1990, p. 3-19.

HART, S. L. A natura-resource-based view of the firm. Academy of Management Review, v.20, n.4, Oct. 1995, p. 986-1014.

HERMAN, S.; KLEIN, R. - Improving the Predictive Power of Conjoint Analysis. Journal of Marketing Research, vol 7 (4), 1995, p.29-31.

HILL, A. C. - As motivações da utilização do Marketing Verde como estratégia empresarial. Dissertação de Mestrado, Departamento de Administração, Pontifícia Universidade Católica do Rio de Janeiro, 1999.

\section{INSTITUTO AKATU e INSTITUTO ETHOS -} Responsabilidade Social das Empresas - Percepção do Consumidor Brasileiro. Pesquisa 2006-2007: Sumário de Conclusões. São Paulo: Instituto Akatu e Instituto Ethos, 2008. Disponível em www.akatu.org.br.

KAUL, A.; RAO, V. R. - Research for product positioning and design decisions: An integrative review. International Journal of Research in Marketing, vol. 12, 1995, p. 293-320.

KEISUKE, N; SHIGEMI, K.; ROKUTA, I.; YUICHI, M. Simple Indicator to Identify the Environmental Soundness of Growth of Consumption and Technology: "Eco-velocity of Consumption”. Environmental Science \& Technology, vol. 41, issue 4, 2007, p. 1465-1472.

KOTLER, P. - Administração de Marketing: Análise, Planejamento, Implementação e Controle. $5^{\text {a }}$ edição, São Paulo: Atlas, 1998.

LAGES, N.; NETO, A. V. - Mensurando a consciência ecológica do consumidor: um estudo realizado na cidade de Porto Alegre. XXVI EnANPAD, Salvador, BA. In: Anais... (CD-ROM), 2002.

MALHOTRA, N. - Pesquisa de Marketing: Uma Orientação Aplicada. Porto Alegre: Bookman, 2006.

MANZINI, E.; VEZZOLLI, C. - O desenvolvimento de produtos sustentáveis: os requisitos ambientais dos produtos industriais. São Paulo: Edusp, 2002.

MARQUES, D. L. de S.-Eco-Atitudes vs Eco-Comportamentos: Os Reflexos da Atitude Ecológica no Comportamento do Consumidor. Dissertação de Mestrado. Departamento de
Administração. Pontifícia Universidade Católica do Rio de Janeiro, 1998.

MINTU-WINSATT, A.; BRADFORD, D. M. - In Search of Market Segments for Green Products. In Environment Marketing: Strategies, Practices, Theory and Research. Edited by Polonsky, Michael \& Mintu-Winsatt, Alma. New York: Haworth Press, 1995.

MOTTA, P. C. - Análise Conjunta. Rio de Janeiro, Pontifícia Universidade Católica do Rio de Janeiro, mímeo, 1997.

MOTTA, S. L. S. - Competitividade Baseada no Marketing Ecológico. Revista de Ciências da Administração, vol. 10, $\mathrm{n}^{\circ}$ 22, set/dez. 2008, p. 128-145.

MOTTA, S. L. S.; ROSSI, G. B. - A influência do fator ecológico na decisão de compra de bens de conveniência: um estudo exploratório na cidade de São Paulo. Revista de Administração USP, São Paulo, v. 38, n.1, jan/mar 2003, p. 46-57.

NEWTON, T. J. - Creating the New Ecological Order? Elias and Actor-Network Theory. The Academy of Management Review, vol. 27, nº 4 , Oct. 2002, p. 523-540.

OTTMAN, J. - Green Marketing: Opportunity for Innovation. New York: Book Surge, $2^{\text {nd }}$ edition, 1994.

$\overline{\text { New York, } 2007 .}$

- Four Green-Marketing Predictions for 2008.

PALHARES, M. F. - O Impacto do Marketing "Verde" nas Decisões Sobre Embalagens das Cervejarias que Operam no Brasil. Dissertação de Mestrado, Faculdade de Economia, Administração e Contabilidade da Universidade de São Paulo (FEA-USP), São Paulo, 2003.

PEREIRA S. J. N.; AYROSA, E. A. T.; FERNANDEZ, P. J. - Dois estudos sobre o Impacto do argumento ecológico em atitudes relativas ao produto e intenção de compra. XXVIII EnANPAD, Curitiba, 25 a 29 de setembro, 2004. In: Anais... Curitiba, 2004.

PIGOU, A. C. - The Economics of Welfare. London: MacMillan, 1920.

PORTNEY, P. R. - Overall Assessment and Future Directions. Public Policies for Environmental Protection. Washington Resources for the Future, 1990.

REINHARDT, F. L. - Bringing the Environment Down to Earth. Harvard Business Review on Business and the Environment. Boston: HBS Press, 2000, p. 35-58.

ROCHA, A. L. P. da; MARQUES, D. L. da S. - Marketing Verde para Quem? XXVIII Encontro Nacional da ANPAD (EnANPAD), Curitiba, Brasil. In: Anais... Curitiba, CD-ROM, 2004.

ROCHA, A. L. P. da. - Desvendando o perfil do consumidor verde: contribuições para os gestores de marketing, $2^{\circ} C A D M A$ Congresso Acadêmico sobre Meio Ambiente e Desenvolvimento, Niterói, Brasil. In: Anais... Niterói, CD-ROM, 2006.

ROCHA, A. L. P. da; SANTOS, T. P. C. dos - Desvendando o perfil do consumidor verde: um estudo longitudinal na cidade do Rio de Janeiro. IX ENGEMA - Encontro Nacional Sobre Gestão Empresarial e Meio Ambiente, Curitiba, 2007. In: Anais... Curitiba, CD-ROM, 2007.

ROCHA, A. L. P. da - Revealing the Brazilian Green Consumer 
Profile: A Study on Rio de Janeiro Citizens and Its Contributions to Marketing Strategists. Readings Book of GBATA's 9th International Conference, Taipei, Taiwan, 2007.

ROCHA, A. L. P. da; BAISCH, L. B.; CASTRO, G. V. de; FAGGIANI, K. C. C.; MOREIRA, L. L. M. - Measuring the Utility Value of Consumers' Goods Ecological Variables. GBATA's Eleventh Annual International Conference, July 7-11, Prague, 2009.

SCHENINI, P. C.; SCHMITT, V.; SILVA, F. A. da; PEREIRA, M. F. - Marketing Verde Como uma Abordagem Estratégica Frente ao Novo Perfil de Consumo. XLIV Congresso da Sociedade Brasileira de Economia e Sociologia Rural (SOBER). Anais... Fortaleza, 23 a 27 de Julho de 2006.

SILVA, J. R. P. C. e - Televisão por Assinatura: Medida de Utilidade dos Atributos que Influenciam as Escolhas dos Consumidores. Dissertação de Mestrado, Departamento de Administração. Pontifícia Universidade Católica do Rio de Janeiro, 1998.

SOLOMON, M. - O Comportamento do Consumidor: Comprando, Possuindo e Sendo. $5^{\text {a }}$ Ed., Porto Alegre: Bookman, 2002.

WAGNER S. A. - Understanding Green Consumer Behavior: A Qualitative Cognitive Approach. London: Routeledge, 1997.

WASIK, J. F. - Green Marketing and Management: a global perspective. Massachusetts: Blackwell, 1996.

ZWERG-VILLEGAS, A. M. - Green Marketing as Strategy of Andean Exporters. GBATA's Eleventh Annual International Conference, July 7-11, Prague, 2009. In: Readings Book..., 2009. 